\title{
UNIFORMIDADE DE DISTRIBUIÇÃO DO POTÁSSIO E DO NITROGÊNIO EM SISTEMA DE IRRIGAÇÃO POR GOTEJAMENTO
}

\author{
MARCUS V. A. M. DE OLIVEIRA ${ }^{1}$, ROBERTO L. VILLAS BÔAS ${ }^{2}$
}

\begin{abstract}
RESUMO: O uso da fertirrigação possibilita a obtenção de bons resultados, todavia é notada a necessidade de trabalhos que venham possibilitar a adoção correta da técnica. Dessa forma ,o presente trabalho buscou comparar a uniformidade de distribuição do potássio e do nitrogênio em sistema de irrigação por gotejamento. A solução de fertilizantes foi injetada durante 25 minutos, sendo recolhidas amostras de solução em diferentes momentos, durante e após ter sido finalizada a operação de injeção, tendo sido especificado o tempo de 35 minutos após o início da operação de injeção da solução de fertilizantes, como tempo-limite para a coleta da última amostra. As amostras coletadas tiveram os teores de potássio $\left(\mathrm{K}^{+}\right)$e nitrogênio $\left(\mathrm{NO}_{3}{ }^{-}+\mathrm{NH}_{4}{ }^{+}\right)$determinados. Com os resultados obtidos, concluiu-se que não houve variação significativa da uniformidade de distribuição de nitrogênio e de potássio no sistema de irrigação por gotejamento; maiores tempos de funcionamento de sistemas de irrigação, quando em operação de fertirrigação, possibilitam melhores uniformidades de distribuição do fertilizante, e deve-se calcular o tempo de lavagem do sistema de irrigação, pois é uma forma de melhorar a uniformidade de distribuição do fertilizante no campo.
\end{abstract}

PALAVRAS-CHAVE: fertirrigação, injeção de fertilizantes, uniformidade de distribuição de fertilizantes.

\section{EVALUATION OF POTASSIUM AND NITROGEN DISTRIBUTION UNIFORMITY IN TRICKLE IRRIGATION SYSTEM}

\begin{abstract}
The use of the fertigation makes possible obtaining good results; however it was noticed the necessity of studies that make possible the correct adoption of this technique. Thus the present study aimed to compare the distribution uniformity of potassium and nitrogen when applied through a trickle irrigation system. The fertilizers solution was applied during 25 minutes; samples of solution were collected at different moments during and after the product injection through irrigation water, and the time limit to collect the last sample was specified as 35 minutes after injection operations begun. In the collected samples were determined the contents of potassium $\left(\mathrm{K}^{+}\right)$ and nitrogen $\left(\mathrm{NO}_{3}{ }^{-}+\mathrm{NH}_{4}{ }^{+}\right)$. According to obtained results, the conclusions were as follows: there is no significant variation on distribution uniformity of nitrogen and potassium in the trickle irrigation system studied; longer periods of irrigation when in fertigation operation, improve uniformity distribution of the fertilizer, and the irrigation period after the fertilizer injection is finalized should be calculated to improve fertilizer distribution uniformity.
\end{abstract}

KEYWORDS: fertigation, fertilizers injection, fertilizers distribution uniformity.

\section{INTRODUÇÃO}

A aplicação de fertilizantes junto à água de irrigação caracteriza a técnica denominada fertirrigação. O emprego dessa técnica tem possibilitado a otimização do uso de insumos em diferentes culturas irrigadas, tanto em aspectos relacionados à produtividade quanto à qualidade dos produtos obtidos, sendo mais notável sua adoção em culturas irrigadas por sistemas de irrigação localizada.

\footnotetext{
${ }^{1}$ Eng ${ }^{\circ}$ Agrônomo, Prof. Dr., Departamento de Recursos Naturais, UNESP, Botucatu - SP, Fone: (0xx14) 3811.7169, marcus_vamo@hotmail.com

${ }^{2}$ Eng ${ }^{\circ}$ Agrônomo, Prof. Adjunto, Departamento de Recursos Naturais, UNESP, Botucatu - SP, rlvboas@fca.unesp.br Recebido pelo Conselho Editorial em: 10-10-2005
}

Aprovado pelo Conselho Editorial em: 30-1-2008 
ZANINI (1987) e VILLAS BÔAS et al.(2003) salientam a necessidade de realizar pesquisas sobre vários aspectos relacionados à fertirrigação, como forma de possibilitar a adoção correta da mesma, uma vez que o emprego eficiente dessa técnica deve levar em consideração aspectos relativos à planta, ao solo e ao sistema de irrigação. A interação entre sistema de irrigação e fertilizantes solubilizados deve ser estudada, visando a garantir uniformidade de distribuição de água e nutrientes.

A formulação da solução a ser injetada no sistema de irrigação tem importante papel na uniformidade de distribuição do fertilizante aplicado via fertirrigação, tendo de ser notados fatores como concentração da solução a ser injetada, tempo de aplicação, solubilidade e pureza dos produtos. ROLSTON et al. (1986) e BURT et al. (1995) relatam que a uniformidade de aplicação dos fertilizantes pode ser influenciada pela variação da concentração da solução no tanque de mistura, uma vez que a mistura pode não ser homogênea. Variações na taxa de injeção planejada e na vazão do sistema também influenciam na uniformidade de distribuição, segundo os mesmos autores.

O tempo de funcionamento do sistema de irrigação, no que diz respeito à operação de fertirrigação, deve ser subdividido em três etapas. A primeira é necessária para que a água chegue a todos os pontos do sistema de irrigação e ocorra a conseqüente estabilização da carga hidráulica no sistema de irrigação. A segunda é compreendida entre o início e o fim da operação de injeção da solução de fertilizantes. Segundo OLIVEIRA et al. (2003), tempos maiores de injeção possibilitam maiores uniformidades de distribuição. A terceira e última etapa é a responsável pela lavagem do sistema, que deverá ser prolongada até que os resíduos dos nutrientes aplicados sejam retirados do sistema pela água de irrigação. SOUSA et al. (2003) concluem que linhas laterais lavadas adequadamente possibilitam maior uniformidade de distribuição dos fertilizantes.

A análise do movimento de qualquer partícula dentro de uma tubulação depende do diâmetro do tubo, das dimensões e da massa específica da partícula, e da aceleração da gravidade. Entretanto, no caso de uma solução, dois processos são responsáveis pela transferência dos nutrientes: fluxo de massa e difusão (CRANCK, 1975). As extremidades das linhas laterais de sistemas de irrigação localizada apresentam como característica o regime hidráulico laminar, no qual a influência da difusão se torna mais efetiva do que em outras porções do sistema de irrigação. MAGALHÃES et al. (1996), estudando a uniformidade de distribuição do potássio e do fósforo em um sistema de irrigação por gotejamento, observaram que, para esses dois elementos, não houve diferença no tempo de avanço desses no sistema, sendo o fluxo massa o processo preponderante.

Dentro desse enfoque, este trabalho buscou comparar a uniformidade de distribuição do potássio e do nitrogênio injetados em um sistema de irrigação por gotejamento, por uma bomba injetora proporcional Dosmatic.

\section{MATERIAL E MÉTODOS}

O experimento foi instalado no Departamento de Engenharia Rural, da Faculdade de Ciências Agronômicas - UNESP, localizada no Câmpus de Botucatu - SP.

O sistema de irrigação localizada por gotejamento utilizado foi dimensionado visando a simular características de concepção e de funcionamento de sistemas utilizados em pomares de citros no interior paulista. Buscou-se fazer uso de linhas laterais de $200 \mathrm{~m}$ de comprimento, uma vez que foi notado que comprimentos semelhantes a esse têm sido utilizados em projetos implantados principalmente por empresas citrícolas de maior porte.

O sistema de irrigação utilizado foi concebido com quatro linhas laterais de polietileno PN 30, com $20 \mathrm{~mm}$ de diâmetro interno e $200 \mathrm{~m}$ de comprimento (Figura 1). Foram instalados pontos para tomada de pressão no início, no meio e no fim das linhas laterais, como forma de monitorar a variação de pressão e localizar possíveis problemas durante os ensaios. 
O espaçamento utilizado foi de $5 \mathrm{~m}$ entre pontos de emissão e $7 \mathrm{~m}$ entre linhas. Para cada ponto de emissão, foi conectada uma mangueira de polietileno com $16,1 \mathrm{~mm}$ de diâmetro interno e $1,5 \mathrm{~m}$ de comprimento, na qual foram instalados quatro gotejadores autocompensantes, marca Netafim, modelo PCJ, com vazão de $8 \mathrm{~L} \mathrm{~h}^{-1}$. A faixa de compensação desse modelo de gotejador, segundo o fabricante, é de 5 a 35 mca. A faixa de compensação do referido gotejador possibilitou que o comprimento de $200 \mathrm{~m}$ da linha lateral fosse utilizado, pois a variação de carga hidráulica nessa situação de dimensionamento, de acordo com a pressão de entrada nas linhas laterais, situava a pressão de trabalho dos emissores dentro da faixa de trabalho proposta pelo fabricante.

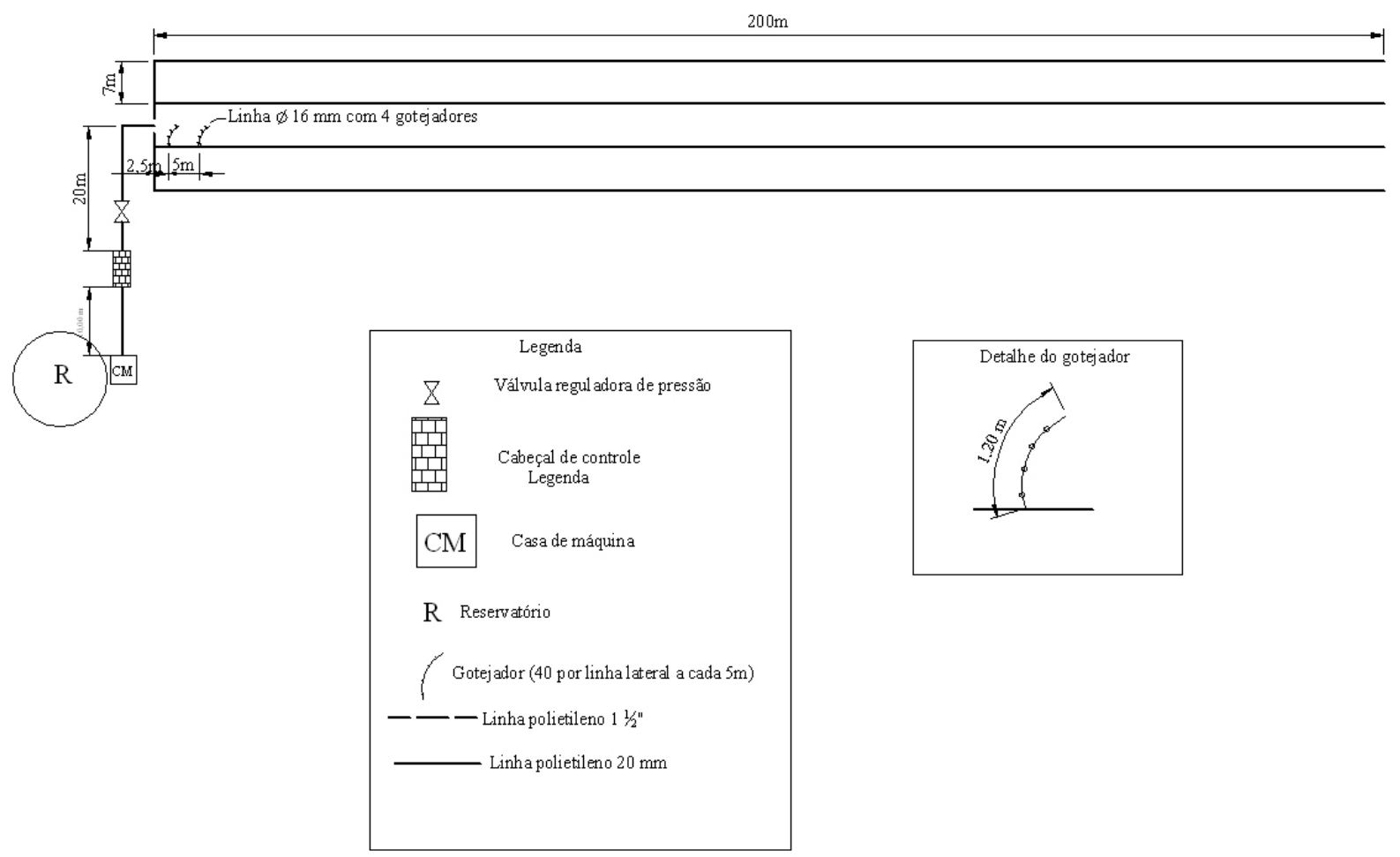

FIGURA 1. Croqui do sistema de irrigação utilizado. Layout of the irrigation system used during the study.

Para a injeção da solução de fertilizantes, foi utilizada uma bomba injetora proporcional, marca DOSMATIC, Modelo A 30. A vazão máxima que esse equipamento pode operar é de $6.700 \mathrm{~L} \mathrm{~h}^{-1}$. A vazão do sistema de irrigação estudado foi de $5.120 \mathrm{~L} \mathrm{~h}^{-1}$, o que atendeu às especificações do injetor.

Após instalado o sistema de irrigação, analisou-se a uniformidade de distribuição de água, utilizando o Coeficiente de Uniformidade de Christiansen (CUC), adotando, como preconizado por BERNARDO (1995), a coleta em oito pontos de cada linha lateral. Não foi realizada nova avaliação da uniformidade de distribuição de água depois de finalizado o experimento. O monitoramento da distribuição de carga hidráulica durante os ensaios demonstrou que não houve variações durante o desenvolvimento dos trabalhos, e conjuntamente ao pouco uso do equipamento inferiu-se que não ocorreram oscilações na uniformidade de distribuição de água no sistema de irrigação em questão no período de estudo.

Nos ensaios, foram utilizados os fertilizantes cloreto de potássio branco $(\mathrm{KCl})$ e nitrato de amônio $\left(\mathrm{NH}_{4} \mathrm{NO}_{3}\right)$. Após a análise, obteve-se que esses fertilizantes possuíam $62 \%$ de $\mathrm{K}_{2} \mathrm{O}$ e $34 \%$ de $\mathrm{N}$, respectivamente. Foram solubilizados para cada ensaio $360 \mathrm{~g}$ de $\mathrm{KCl}$ e $585 \mathrm{~g}$ de nitrato de amônio em $41 \mathrm{~L}$ de água. Essas quantidades de fertilizantes foram utilizadas como forma de obter a mesma quantidade de $\mathrm{N}$ e $\mathrm{K}$ nas amostras coletadas, uma vez que estavam sendo injetados no sistema aproximadamente $190 \mathrm{~g}$ de cada um desses elementos. Como forma de garantir maior homogeneidade da solução, fez-se uso de agitador elétrico. 
A amostragem de solução foi realizada em oito pontos regularmente espaçados de $28,6 \mathrm{~m}$ em relação à linha lateral.

A injeção dos fertilizantes no sistema de irrigação foi realizada durante o período de 25 minutos, com quatro repetições. Durante a injeção, foram recolhidas cinco amostras por ponto de coleta a cada 5 minutos. Após o término da injeção da solução de fertilizantes, foram coletadas, nos 10 minutos subseqüentes, duas amostras de solução, ou seja, aos 30 e 35 minutos após ter sido iniciada a injeção da solução de fertilizante. Exemplificando, foram coletadas amostras a 5; 10; 15; 20; 25; 30 e 35 minutos após o início da injeção da solução de fertilizantes.

Para cada intervalo, coletou-se todo o volume de solução em garrafas tipo "pet” de 2 L, retirando-se uma subamostra em recipientes de plástico de $80 \mathrm{~mL}$. As amostras coletadas foram encaminhadas ao Laboratório de Fertilizantes e Corretivos do Departamento de Recursos Naturais/Ciência do Solo, para serem determinados os teores de potássio $\left(\mathrm{K}^{+} \mathrm{mg} \mathrm{L}^{-1}\right)$ e de nitrogênio $\left(\mathrm{NO}_{3}^{-}+\mathrm{NH}_{4}^{+} \mathrm{mg} \mathrm{L}{ }^{-1}\right)$.

Os dados obtidos durante o experimento foram analisados em relação à uniformidade de distribuição dos fertilizantes nas linhas de irrigação, temporalmente e espacialmente. Foram determinados os valores de coeficiente de variação (C.V.) para avaliar a distribuição do potássio e do nitrogênio, procedendo-se à análise de variância das quantidades de fertilizantes aplicadas ao longo das linhas laterais.

\section{RESULTADOS E DISCUSSÃO}

O sistema de irrigação apresentou coeficiente de uniformidade de Christiansen (CUC) de 97,70\% para a aplicação de água. BERNARDO (1995) cita que o valor aceitável desse coeficiente para sistemas de irrigação localizada é de $80 \%$, demonstrando que o sistema funcionava adequadamente.

Determinou-se o tempo necessário para a água atingir todos os pontos da linha de irrigação a partir do momento de passagem pelo cabeçal de controle do sistema. A determinação do tempo de deslocamento, bem como da velocidade da água, foi obtida após haver sido verificada a estabilização da carga hidráulica e da vazão em todo o sistema. Na Figura 2, observam-se o tempo de deslocamento da água e a velocidade na linha lateral. Foram necessários aproximadamente 13,5 minutos para a chegada da água nos últimos emissores.

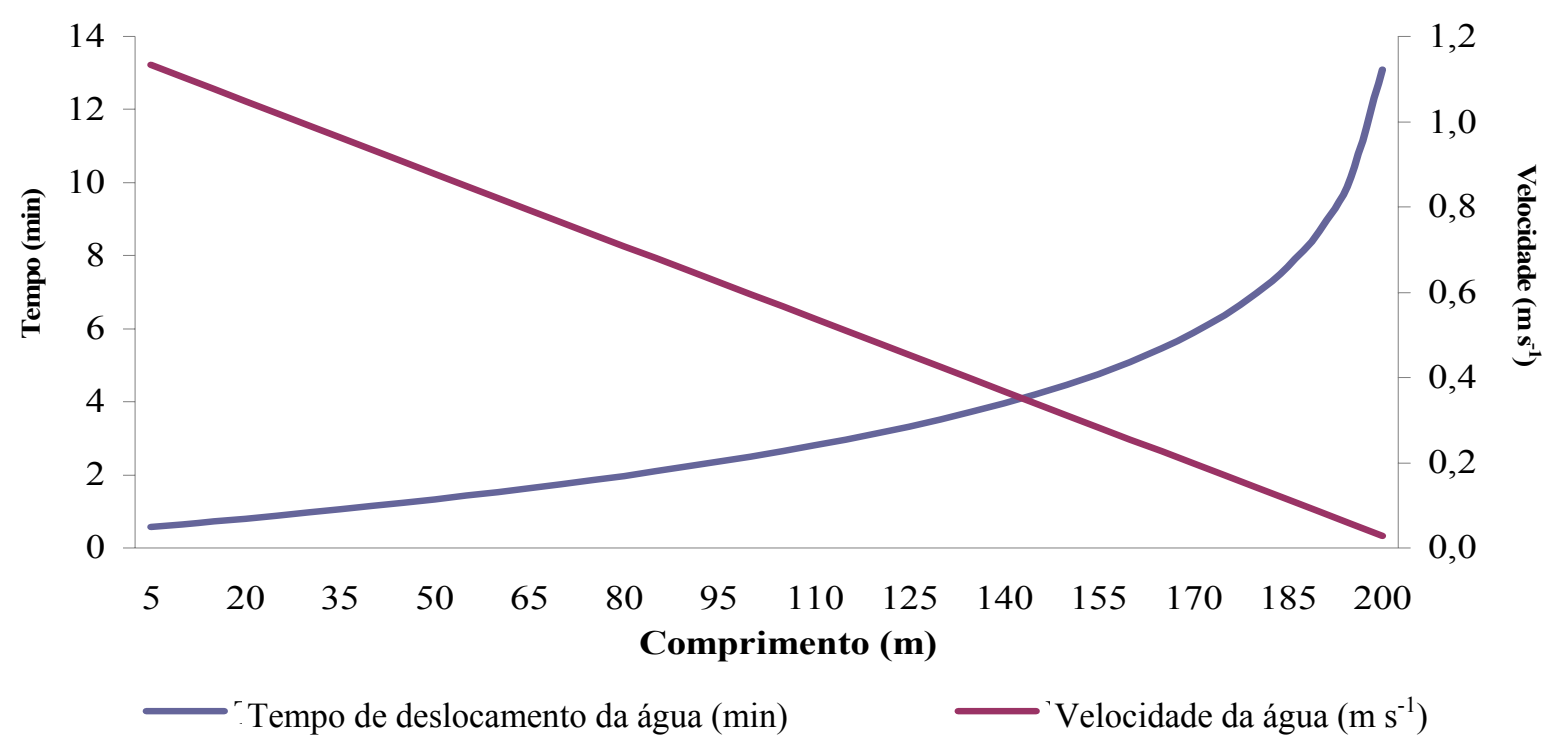

FIGURA 2. Tempo para a água atingir os diferentes pontos das linhas laterais. Necessary time for irrigation water to reach different points of the lateral lines. 
Sendo a água o veículo para o transporte dos fertilizantes injetados, pode-se considerar que o tempo de percurso desses dentro do sistema de irrigação depende da velocidade de caminhamento da água. Infere-se que o início da fertirrigação nas linhas laterais se dá em tempo igual ao tempo necessário para uma gota de água de irrigação atingir esse ponto do sistema, contado a partir do cabeçal de controle.

Autores como SOUZA et al. (1997) e OLIVEIRA (2003) também observaram que a velocidade da água na linha de irrigação define o tempo em que o fertilizante atinge os diferentes pontos de um sistema de irrigação, não sendo influenciado por fatores como variação da taxa de injeção e tipo de injetor utilizado. Na Figura 3, corrobora-se o fato indicado, uma vez que demonstra para o intervalo de tempo estudado a dinâmica da concentração de ambos os nutrientes no decorrer das linhas de irrigação. Nos pontos situados no início das linhas laterais, mais notadamente nos situados a 5 e $30 \mathrm{~m}$, a concentração alcançou os valores máximos assim que começou a mensuração da concentração de nutrientes na água de irrigação. $\mathrm{Na}$ extremidade final das linhas, valores de concentração próximos aos máximos atingidos durante a observação de todo o sistema começaram a ser mensurados, aproximadamente, no mesmo tempo observado para o caminhamento da água do início ao fim das linhas laterais.

De acordo com OLIVEIRA (2006), a curva de distribuição da solução de fertilizantes em qualquer ponto de um sistema de irrigação localizada tende a seguir o modelo polinomial de segundo grau, ou seja, em qualquer ponto há, num primeiro momento, menor concentração dos nutrientes injetados na água; com o prosseguimento do processo, há aumento da concentração até atingir o valor máximo, e após esse pico de concentração ocorre o decréscimo até que não exista mais fertilizante a ser aplicado. A análise gráfica do perfil da distribuição da concentração de $\mathrm{K}$ e $\mathrm{N}$ ao longo do comprimento das linhas laterais para o tempo amostrado, representada na Figura 3, evidencia que, para ambos os nutrientes, houve a mesma tendência de distribuição, conforme relatado por OLIVEIRA (2006).

O gráfico que representa os pontos situados a $5 \mathrm{~m}$ do início das linhas laterais demonstra essa dinâmica do processo de distribuição dos fertilizantes em sistemas de irrigação localizada. O tempo de funcionamento do sistema de irrigação depois de finalizada a operação de injeção não foi suficiente para garantir que todo o fertilizante injetado fosse aplicado, e, conseqüentemente, o sistema estivesse lavado, uma vez que o gráfico representativo do ponto situado a $200 \mathrm{~m}$ mostra que, naquele ponto, a concentração dos nutrientes ainda apresentava valores máximos.

Foram calculadas as quantidades de potássio e nitrogênio que foram aplicadas em cada ponto durante o período estudado (Figura 4). Observa-se que a quantidade aplicada de nitrogênio tendeu a ser superior à quantidade aplicada de potássio. Entretanto, a análise de variância dos valores aplicados nos diferentes pontos ao longo das linhas laterais demonstrou que não houve diferença estatística quanto à aplicação desses nutrientes, sendo as quantidades médias aplicadas de $1.111,38 \mathrm{mg}$ para K e 1.147,33 mg para N.

MAGALHÃES et al. (1996) compararam a uniformidade de distribuição do potássio e do fósforo em um sistema de irrigação localizada por gotejamento, com linhas laterais de $90 \mathrm{~m}$ de comprimento, concluindo que também não houve diferença estatística quanto à uniformidade de distribuição, inferindo que não há diferença na velocidade de transporte dos nutrientes quando aplicados em operações de fertirrigação.

O movimento de nutrientes em uma linha de irrigação dá-se predominantemente por fluxo de massa, todavia, na parte final das linhas laterais de sistemas de irrigação localizada, onde o regime hidráulico preponderante é o laminar, a ação do movimento via difusão tem maior representatividade, como observado por SAMPAIO et al. (1997). Entretanto, de acordo com o observado neste trabalho, a maior ação do movimento de difusão nas extremidades das linhas laterais não possibilitou que houvesse a chegada de diferentes quantidades dos nutrientes estudados naqueles pontos. 
A dinâmica da concentração da solução de fertilizantes dentro do sistema de irrigação, no que diz respeito ao tempo necessário para que todos os pontos do sistema sejam alcançados, e, conseqüentemente, possa ser atingida uniformidade de aplicação adequada, pode ser determinada pela equação da continuidade. Sendo, nessa equação, a velocidade do fluido, função da vazão e da área da seção de escoamento, infere-se a partir dos dados apresentados que, no caso da solução de fertilizantes aplicada via fertirrigação, a velocidade independe dos fertilizantes utilizados. A relação entre área da seção e vazão do sistema é que define o tempo para que a aplicação da solução de fertilizantes seja a mais uniforme possível.
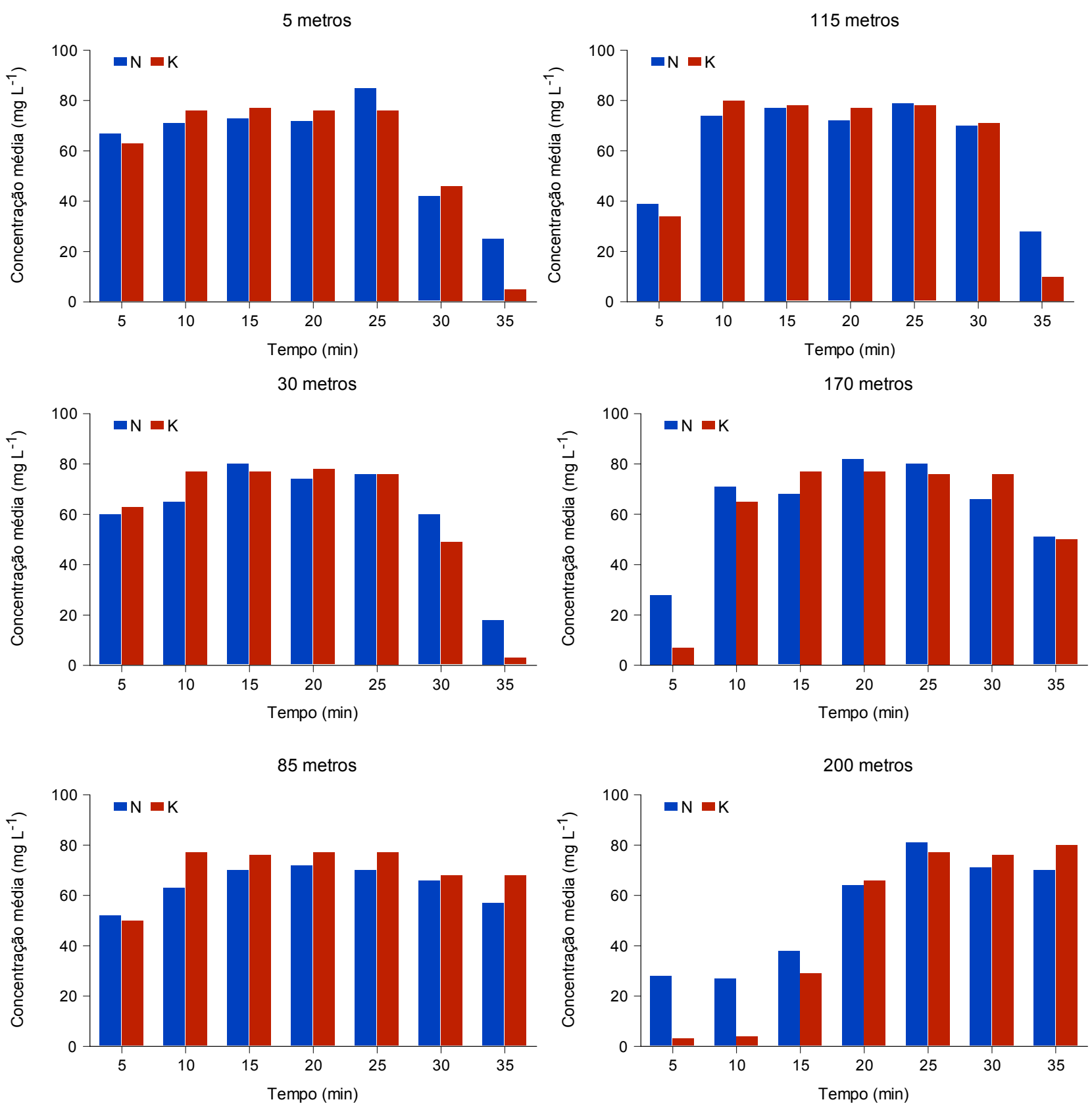

FIGURA 3. Concentração média $\left(\mathrm{mg} \mathrm{L}^{-1}\right)$ de $\mathrm{N}\left(\mathrm{NO}_{3}{ }^{-}+\mathrm{NH}_{4}{ }^{+}\right)$e $\mathrm{K}^{+}$nos pontos de amostragem nas linhas laterais, para os diferentes intervalos de tempo empregados. $\mathbf{N}\left(\mathbf{N O}_{3}{ }^{-}+\mathbf{N H}_{4}{ }^{+}\right)$ and $K_{+}$average concentration through the lateral lines. 

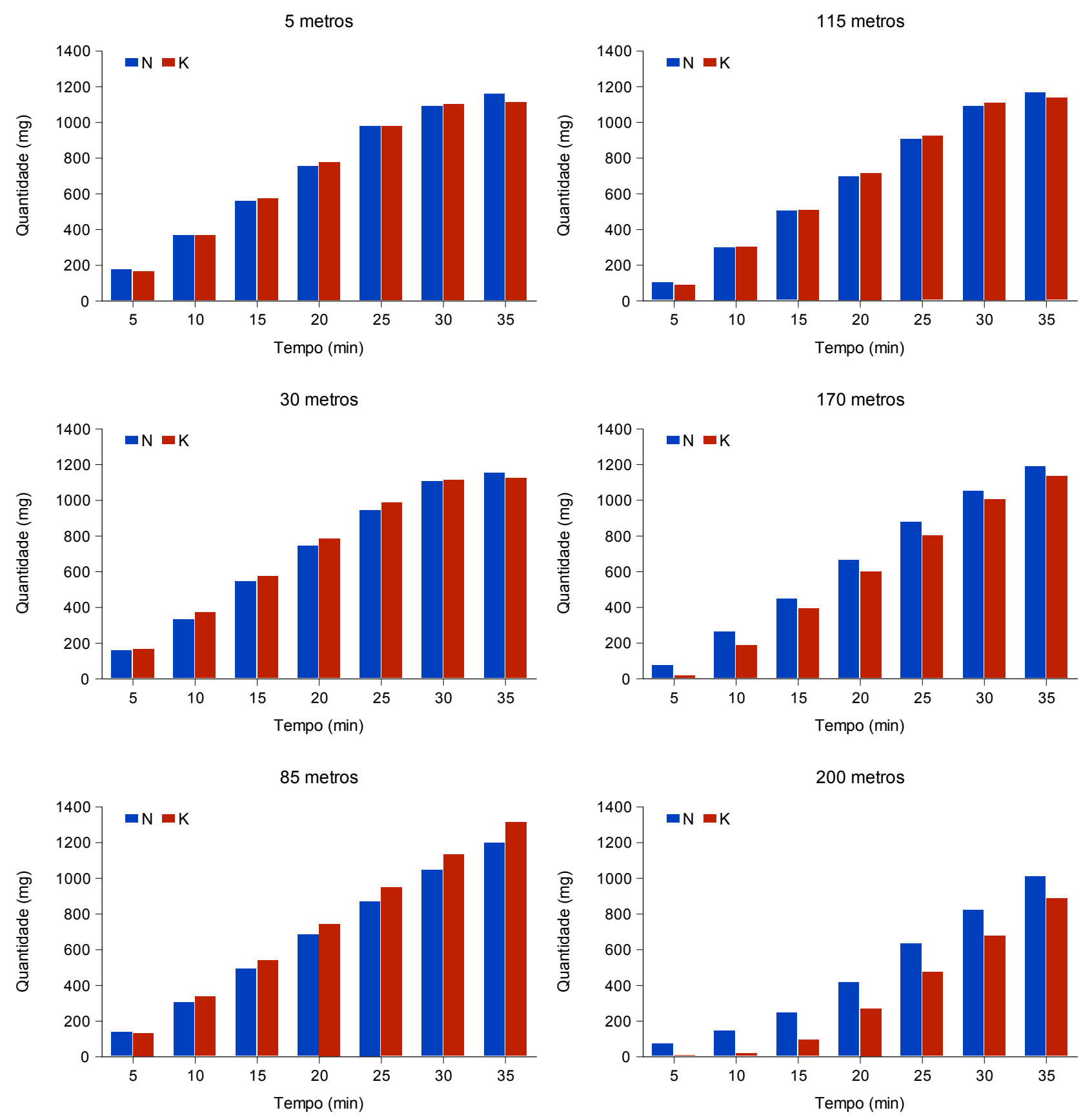

FIGURA 4. Quantidades médias (mg) de $\mathrm{N}$ e $\mathrm{K}$ aplicadas nos pontos de amostragem nas linhas laterais, para os intervalos de tempo empregados. Average amounts of $\mathbf{N}$ and $\mathbf{K}$ applied to different points observed in the lateral lines studied.

Os coeficientes de variação calculados foram de 10,84\% para potássio, e de 6,06\% para nitrogênio, no intervalo final de amostragem. Durante o período de injeção de 25 minutos, os coeficientes de variação foram de $23,10 \%$ e $14,18 \%$ para potássio e nitrogênio, respectivamente. $\mathrm{O}$ período de lavagem do sistema de irrigação, após a injeção do fertilizante, colaborou para melhorar a uniformidade de distribuição dos fertilizantes. A uniformidade de aplicação de fertilizantes em sistemas de irrigação independe do nutriente ou da fonte utilizados, e, sim, mais notadamente do tempo de funcionamento do sistema. OLIVEIRA (2002), ALVES (1992) e HOLMAN (1978) indicam que, quanto maior o tempo de injeção do sistema, maior é a uniformidade de distribuição. Contudo, somente o tempo de injeção não possibilita que sejam obtidas uniformidades de distribuição adequadas. É necessário que seja levado em consideração todo o tempo de funcionamento do sistema: tempo de injeção e tempo para a condução da solução de fertilizante até o ponto extremo do sistema, ou seja, tempo de lavagem. 
Comparativamente, os valores de coeficiente de variação de aplicação de fertilizantes via fertirrigação, tanto para o período final de amostragem (35 minutos), quanto para o período de injeção da solução de fertilizantes (25 minutos), ou seja, período no qual a última etapa da operação de fertirrigação ainda não tinha-se findado, foram melhores que os encontrados por SAMPAIO (1997), para potássio, em adubação convencional, que foi de $17,58 \%$. Dessa forma, o emprego da técnica de fertirrigação em termos de uniformidade de distribuição de fertilizantes tem melhor resultado que a prática de distribuição convencional de fertilizantes, uma vez que é possível que seja alcançada uniformidade igual à própria uniformidade de distribuição de água do sistema. Todavia, assim como enfatizado por diversos autores, para obter sucesso no emprego da fertirrigação, é necessário buscar otimização de vários fatores referentes ao emprego da técnica, sendo a uniformidade de distribuição um dos fatores mais importantes.

\section{CONCLUSÕES}

Não houve variação significativa da uniformidade de distribuição de nitrogênio e de potássio no sistema de irrigação localizada.

Maiores tempos de funcionamento de sistemas de irrigação, quando em operação de fertirrigação, possibilitam melhores uniformidades de distribuição do fertilizante.

Deve-se calcular o tempo de lavagem do sistema de irrigação, pois é uma forma de melhorar a uniformidade de distribuição do fertilizante no campo.

\section{REFERÊNCIAS}

ALVES, D. N. B. Desempenho da bomba injetora e do tanque de derivação de fluxo na aplicação de cloreto de potássio em microaspersão. 1992. 72 f. Dissertação (Mestrado em Irrigação e Drenagem) - Escola Superior de Agricultura de Lavras, Lavras, 1992.

BERNARDO, S. Manual de irrigação. 6.ed. Viçosa: UFV, Imprensa Universitária, 1995. 657 p.

BURT, C.; O'CONNOR, K.; RUEHR, T. Fertigation. California: The Irrigation Training Research Center. Polytechnic State University, 1995. 320 p.

CRANCK, J. The mathematics of diffusion. New York: Oxford University Press, 1975. 415 p.

HOLMAN, H. Fertilizer and chemical injection for irrigation systems. Citrus \& Vegetable Magazine, Tampa, v.41, n.26-28, p.46-8, 1978.

MAGALHÃES, M.I.; TEXEIRA, A.S.; FERREYRA, F.F. Uniformidade de distribuição do fertilizante, via fertirrigação, em um sistema de irrigação por gotejamento. In: CONGRESSO BRASILEIRO DE ENGENHARIA AGRÍCOLA, 25., 1996, Bauru. Anais... Bauru: UNESP/ Sociedade Brasileira de Engenharia Agrícola, 1996. 1 CD-ROM.

OLIVEIRA, M.V.A.M. de. Modelo para estimativa do tempo de fertirrigação. 2006. 90 f. Tese (Doutorado em Irrigação e Drenagem) - Faculdade de Ciências Agronômicas, Universidade Estadual Paulista, Botucatu, 2006.

OLIVEIRA, M.V.A.M. de. Uniformidade de distribuição temporal e espacial do KCl na fertirrigação, em um sistema de irrigação por gotejamento. 2002. 75 f. Dissertação (Mestrado em Irrigação e Drenagem) - Faculdade de Ciências Agronômicas, Universidade Estadual Paulista, Botucatu, 2002.

OLIVEIRA, M.V.A.M. de; VILLAS BÔAS, R.L.; GARCIA, C.J.B.; NASCIMENTO, F.R. Uniformidade de distribuição de potássio num sistema de irrigação por gotejamento quando aplicado por diferentes injetores. Irriga, Botucatu, v.8, n.3, p.234-41, 2003.

ROLSTON, D.E.; MILLER, R.J.; SCHULBACH, H. Management principles-fertilization. In: NAKAYAMA, F.S; BUCKS, D.A. Trickle irrigation for crops production, developments in agricultural engineering. Amsterdam: Elsevier, 1986. 383 p. 
SAMPAIO, S.C.; FARIA, M.A.de; LIMA, L.A.; OLIVEIRA, M.S. de; SILVA, A.M. Fertirrigação simulada em linhas de gotejadores. Engenharia Rural, Piracicaba, v.7, n. único, p.50-61, 1996.

SOUSA, V.F. de.; FOLEGATTI, M.V.; FRIZZONE, J.A.; CORRÊA, R.A.de L.; ALENCAR, C.M. Distribuição de fertilizantes em um sistema de fertirrigação por gotejamento. Revista Brasileira de Engenharia Agricola e Ambiental, Campina Grande, v.7, n.1, p.186-9, 2003.

SOUZA, G.H.F.; NOGUEIRA, F.C.; MEDEIROS, J.F.; NETO, J.M. Efeitos da variação da vazão do injetor de fertilizantes em diferentes tempos de aplicação na uniformidade de distribuição do adubo em irrigação por gotejamento. In: CONGRESSO BRASILEIRO DE ENGENHARIA AGRÍCOLA, 26., 1997, Campina Grande. Anais... Campina Grande: UFPB/Sociedade Brasileira de Engenharia Agrícola, 1997. 1 CD-ROM.

VILLAS BÔAS, R.L.; OLIVEIRA, M.V.M. de; MOTA, P.R.A; BETTINI, M.O. Fertirrigação no Brasil, técnica inovadora nos cultivos irrigados. In: CONGRESSO BRASILEIRO DE FERTIRRIGAÇÃO, 1., 2003, João Pessoa 2003. Anais... João Pessoa: UFPB/CCA, 2003. 1 CDROM.

ZANINI, J.R. Hidráulica da fertirrigação por gotejamento utilizando o tanque de derivação de fluxo e bomba injetora. 1987. 103 f. Tese (Doutorado em Solos e Nutrição de Plantas) - Escola Superior de Agricultura “Luís de Queiroz”, Universidade de São Paulo, Piracicaba, 1987. 